\title{
Renin-Angiotensin System Inhibitors and COVID-19: a Systematic Review and Meta-Analysis. Evidence for Significant Geographical Disparities
}

\author{
Dimitrios Patoulias ${ }^{1} \cdot$ Alexandra Katsimardou ${ }^{1} \cdot$ Konstantinos Stavropoulos $^{1} \cdot$ Konstantinos Imprialos $^{1}$. \\ Maria-Styliani Kalogirou ${ }^{1} \cdot$ Michael Doumas ${ }^{1}$
}

Accepted: 20 August 2020 / Published online: 10 September 2020

(C) Springer Science+Business Media, LLC, part of Springer Nature 2020

\begin{abstract}
Purpose of Review While the COVID-19 pandemic is constantly evolving, it remains unclear whether the use of angiotensinconverting enzyme (ACE) inhibitors or angiotensin receptor blockers (ARBs) affects the clinical course of SARS-CoV-2 infection. For this meta-analysis, PubMed, CENTRAL, and grey literature were searched from their inception to 19 May 2020 for randomized, controlled trials or observational studies that evaluate the association between the use of either ACE inhibitors or ARBs and the risk for major clinical endpoints (infection, hospitalization, admission to ICU, death) in adult patients during the COVID-19 pandemic. In addition, a subgroup geographical analysis of outcomes was performed. Studies including less than 100 subjects were excluded from our analysis.

Recent Findings In total, 25 observational studies were included. ACE inhibitors and ARBs were not associated with increased odds for SARS-CoV-2 infection, admission to hospital, severe or critical illness, admission to ICU, and SARS-CoV-2-related death. In Asian countries, the use of ACE inhibitors/ARBs decreased the odds for severe or critical illness and death $(\mathrm{OR}=0.37$, $95 \%$ CI $0.16-0.89, I^{2}=83 \%$, and OR $=0.62,95 \%$ CI $0.39-0.99, I^{2}=0 \%$, respectively), whereas they increased the odds for ICU admission in North America and death in Europe $\left(\mathrm{OR}=1.75,95 \%\right.$ CI $1.37-2.23, I^{2}=0 \%$, and $\mathrm{OR}=1.68,95 \%$ CI $1.05-2.70$, $I^{2}=82 \%$, respectively). ACE inhibitors might be marginally protective regarding SARS-CoV-2-related death compared with ARBs $\left(\mathrm{OR}=0.86,95 \%\right.$ CI $\left.0.74-1.00, I^{2}=0 \%\right)$.

Summary Randomized controlled trials are needed to confirm the aforementioned associations between ACE inhibitors, ARBs, and SARS-CoV-2.
\end{abstract}

Keywords SARS-CoV-2 - COVID-19 - Hypertension · Angiotensin-converting enzyme inhibitors · ACE inhibitors · Angiotensin receptor blockers $\cdot$ ARBs $\cdot$ Renin-angiotensin inhibitors $\cdot$ RAS inhibitors

This article is part of the Topical Collection on Guidelines / Clinical Trials/Meta-Analysis

Electronic supplementary material The online version of this article (https://doi.org/10.1007/s11906-020-01101-w) contains supplementary material, which is available to authorized users.

Michael Doumas

michalisdoumas@yahoo.co.uk

1 Second Propedeutic Department of Internal Medicine, Aristotle University of Thessaloniki, General Hospital "Hippokration", Konstantinoupoleos 49, 54642 Thessaloniki, Greece

\section{Introduction}

Last December, a novel coronavirus contaminated a first cluster of Chinese patients in Wuhan [1]. A severe acute respiratory syndrome coronavirus (SARS-CoV)-2 has spread rapidly around the globe reaching a pandemic status during the first trimester of 2020. Currently, the coronavirus disease 2019 (COVID-19), caused by the SARS-CoV2 , accounts for more than 5,500,000 cases and 350,000 deaths worldwide, along with unprecedented detrimental effects on healthcare systems and global economy [2]. Therefore, widespread intense efforts are applied to better understandCOVID-19 and expand our knowledge in several clinically meaningful aspects. 
Initial reports demonstrated that similar to the previous SARS-CoV, the novel SARS-CoV-2 employs angiotensinconverting enzyme 2 (ACE2) as the receptor to infect human cells through its spike protein $[3,4]$. Consequently, this specific interaction has been postulated as a potential factor in SARS-CoV-2 infectivity [5], and concerns were generated about the use of renin-angiotensin (RAS) inhibitors in patients with hypertension, diabetes mellitus, and cardiovascular disease [6-9]. Indeed, some media sources, health systems, and scientists suggested the discontinuation of RAS inhibitors, until more data is available.

However, an abundance of clinical data in millions of patients robustly documents that RAS inhibitors provide significant benefits in patients with cardiovascular disease. In brief, RAS inhibitors reduce major cardiovascular adverse events and mortality in a wide cluster of diseases, such as hypertension, myocardial infarction, cerebrovascular disease, heart failure with reduced ejection fraction, left ventricular hypertrophy, and albuminuria [10,11]. Consequently, withdrawal of RAS inhibitors in those very high-risk patients might result in clinical instability and adverse health outcomes, which in turn might increase both mortality and the need of hospitalization during the pandemic, when healthcare systems are highly overwhelmed.

Altogether, the use of RAS inhibitors emerged as a fundamental health issue in COVID-19 pandemic, but existing data - either experimental or clinical - seems pretty conflicting and scarce. Towards this end, we conducted a systematic review and meta-analysis of clinical studies assessing the association of RAS inhibitors with COVID-19 infectivity, severity (need for hospitalization, admission to intensive care unit (ICU)), and mortality. We also sought to unveil potential differences between angiotensin-converting enzyme (ACE) inhibitors and angiotensin receptor blockers (ARBs) in these outcomes, as well as potential disparities in different continents.

\section{Systematic Review and Meta-Analysis}

\section{Methods}

This systematic review and meta-analysis are reported according to the preferred reporting items for systematic reviews and meta-analyses (PRISMA) statement [12].

\section{Eligibility Criteria}

We searched for available randomized controlled trials or observational studies, regardless of study duration, enrolling adult patients, and evaluating the association between the use of either ACE inhibitors or ARBs and the risk (or odds) for major clinical endpoints in the context of infection from
SARS-CoV-2 during the COVID-19 pandemic. We planned to exclude studies enrolling patients aged less than 18 years and studies including less than 100 subjects.

We did not implement any restriction regarding study setting.

\section{Search Strategy}

We performed a systematic search in two major electronic databases, PubMed and Cochrane Central Register of Controlled Trials (CENTRAL), from their inception to 19 May 2020. MeSH terms were used for both therapeutic interventions, along with free-text words. We also used the Boolean operators "OR" and "AND." Our search was therefore restricted to human studies. We did not impose any filter regarding language, text availability, and publication date. Search strategy in the two major databases is provided in supplementary appendix (supplementary tables 1 and 2).

Grey literature was searched, as well. We searched the clinicaltrials.gov (supplementary table 3 ) and the medRxiv. org from inception to 19 May 2020. Reference lists of all eligible studies were handsearched, as well. Search strategy was reviewed upon the PRESS 2015 Guideline Statement [13].

Finally, we planned to contact authors of identified studies for retrieving missing or unclear data.

\section{Study Selection}

All retrieved reports were imported into reference software manager (Mendeley@) for deduplication. After that, remaining reports were reviewed at title and abstract level by two independent reviewers (D.P. and A.K.). Potentially eligible studies were full-text assessed. Any discrepancies among the two reviewers at any stage were resolved by discussion, consensus, or arbitration by a third senior reviewer (M.D.). Eligible reports from grey literature were cross-checked with the results retrieved from electronic databases. The study selection process is depicted in the corresponding flow diagram (Fig. 1).

\section{Data Extraction}

Two independent reviewers (D.P. and A.K.) extracted the data from the eligible reports, by using a pilot tested, data extraction form developed in Microsoft Excel@.

Extracted information included the following: source characteristics, study characteristics, participants' baseline characteristics, interventions, and comparators (if any), along with key clinical outcomes. We defined the following major clinical endpoints as outcomes of our systematic review and meta-analysis: 

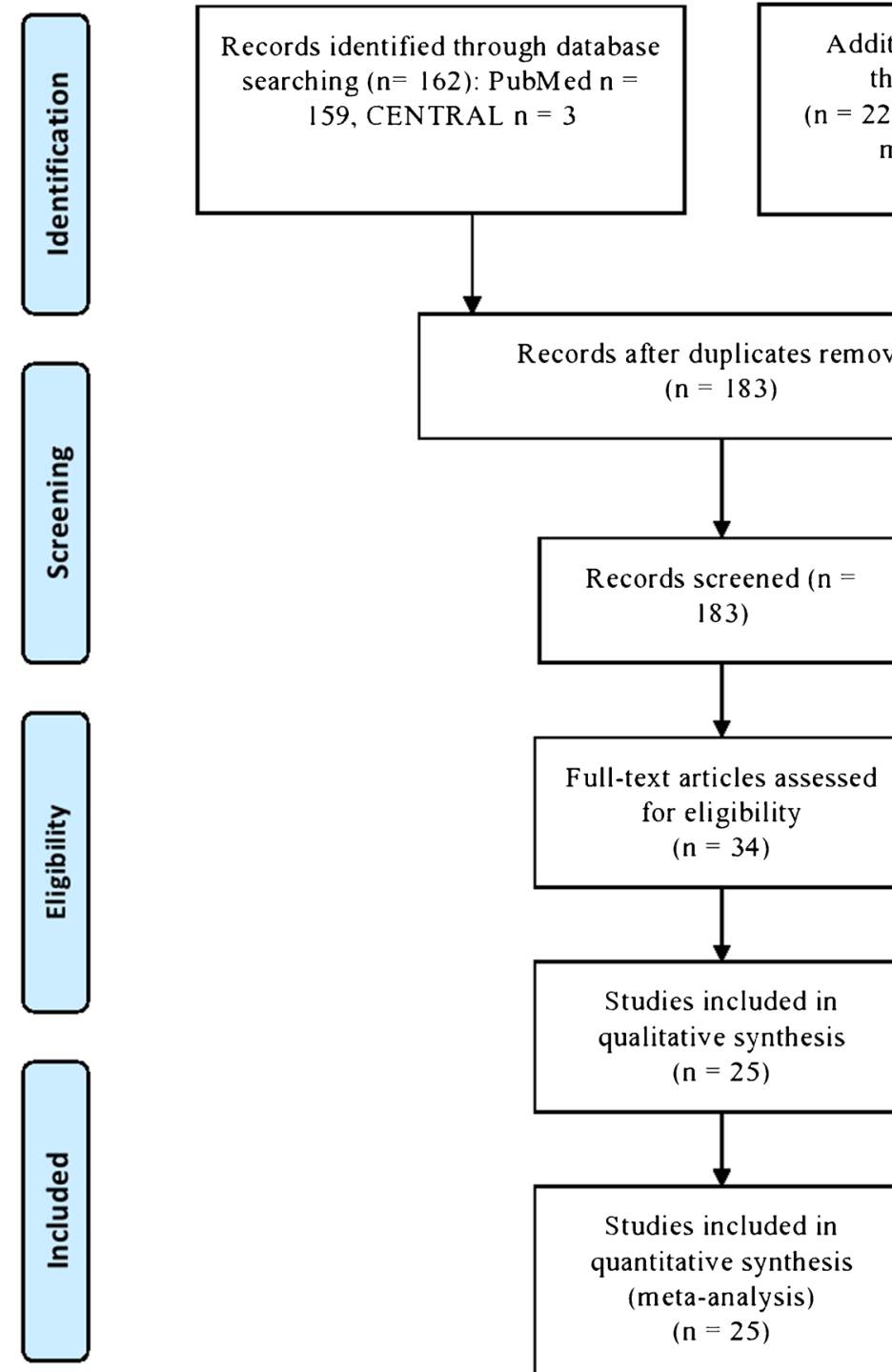

Additional records identified through other sources $(\mathrm{n}=22)$ : clinicaltrials.gov $\mathrm{n}=0$, medRxiv.org $n=22$

Fig. 1 Flow diagram depicting the study selection process

1. testing positive for SARS-CoV-2 (defined as primary outcome)

2. admission to hospital

3. development of severe or critical illness

4. admission to ICU

5. SARS-CoV-2-related death

If the results of a study were reported in multiple articles or at different follow-up time points, we preferred data extracted from journal articles, while we used the reports with the longest duration or the larger sample size.

We also planned to conduct additional subgroup analyses, if data were available, to assess the impact of RAS blockers on the aforementioned outcomes according to region (Asia, Europe, North America, etc.), gender, race/ethnicity, and main co-morbidities (cardiovascular disease, diabetes mellitus, chronic kidney disease, chronic respiratory failure). We also evaluated the impact of ACE inhibitors vs. ARBs on outcomes of clinical interest (SARS-CoV-2-positive testing and related death, admission to ICU).

\section{Risk of Bias Assessment}

Two independent reviewers (D.P. and K.S.) assessed the quality of the included RCTs, by using the Revised Cochrane risk of bias tool for randomized trials (RoB 2.0) [14]. Each domain was rated as low, unclear, or high risk of bias. Presence of adequate procedures in all domains rated a study as being of low risk of bias, while inadequate procedure in at least one domain rated a study as being of high risk of bias. The same reviewers assessed the quality of the included observational studies with the use of the Newcastle-Ottawa Scale (NOS) [15].The NOS assigns up to a maximum of 9 points for the risk of bias in 3 domains: (1) selection of study groups (4 


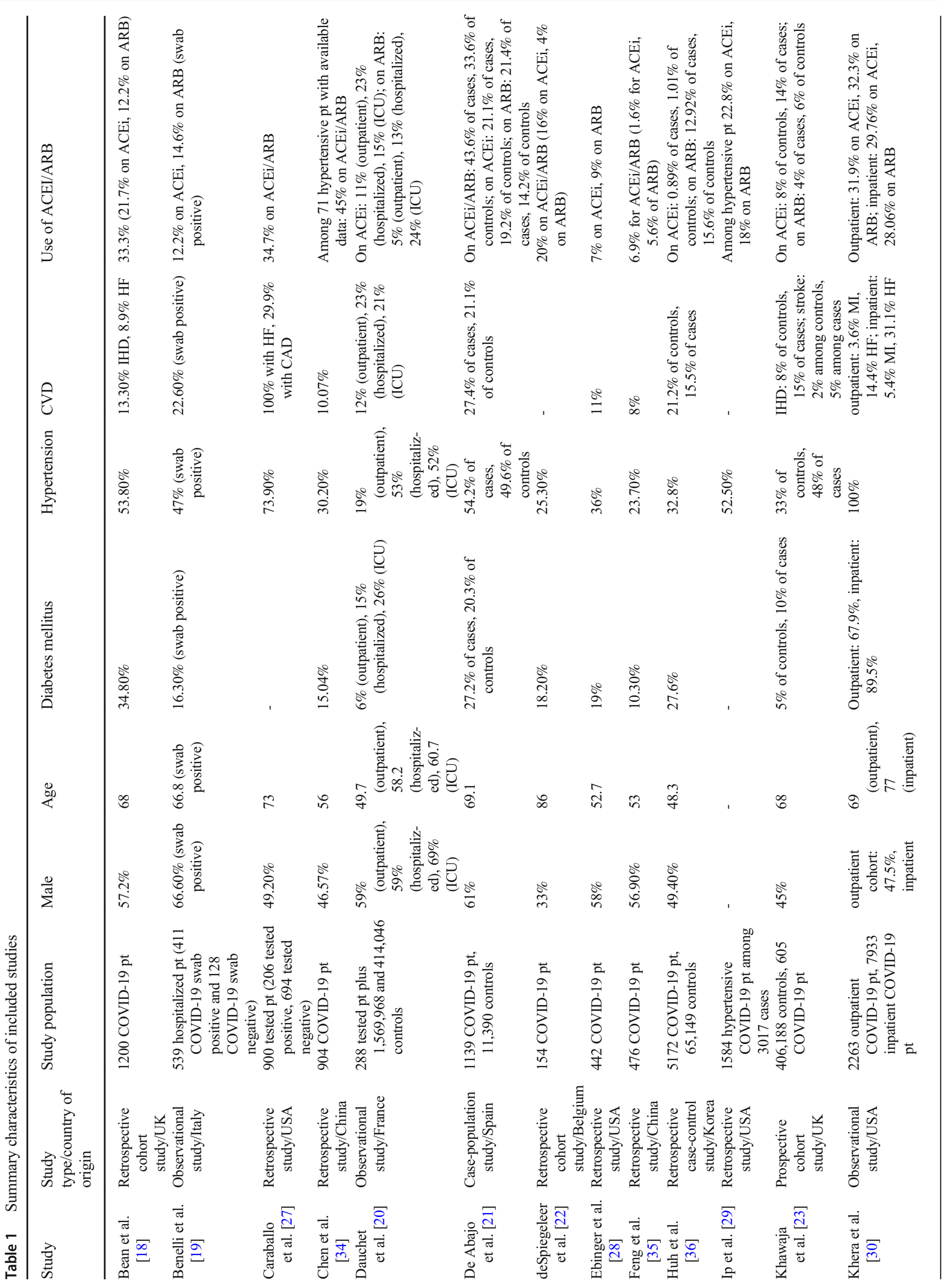




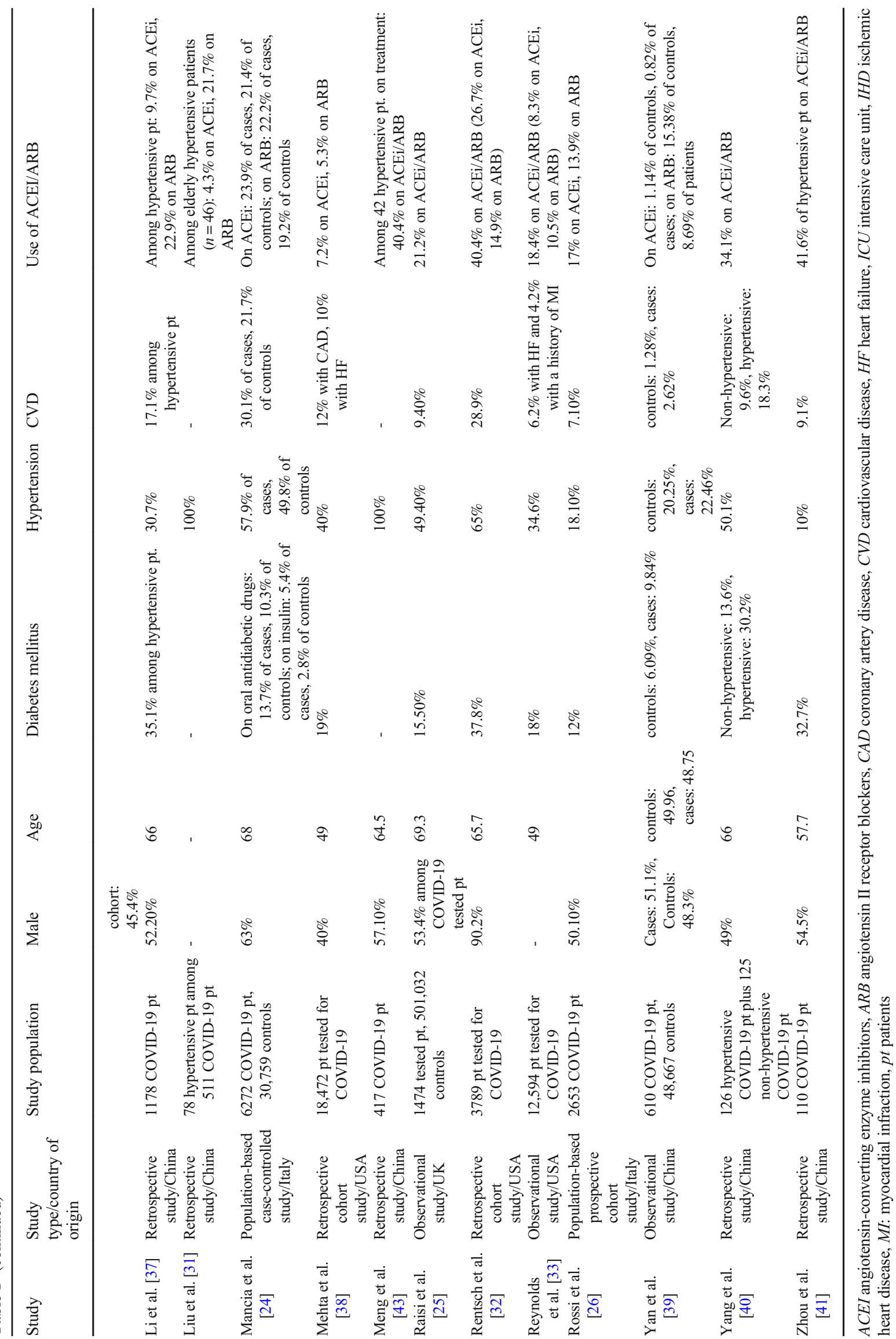


points), (2) comparability of groups (2 points), and (3) ascertainment of exposure and outcomes ( 3 points) for case-control and cohort studies, respectively.

Discrepancies between reviewers were solved by discussion, consensus, or arbitration by a third senior reviewer (M.D.). Risk of bias assessment across the selected studies is provided in Table 2 .

\section{Data Synthesis and Analysis}

Since we planned to assess major clinical endpoints representing dichotomous variables, differences were calculated with the use of odds ratio (OR), with $95 \% \mathrm{CI}$, after implementation of the Mantel-Haenszel (M-H) random effects formula. Statistical heterogeneity among studies was assessed by using $I^{2}$ statistics. Heterogeneity was considered to be low if $I^{2}$ was between 0 and 25\%, moderate if $I^{2}$ was between 25 and $50 \%$, or high if $I^{2}$ was greater than $75 \%$ [16].

All analyses were performed at the 0.05 significance level, while they were undertaken with the RevMan 5.3 software [17].

\section{Results}

We identified 183 records after implementing our search strategy in major databases and grey literature up to 19 May 2020. We assessed 34 full-text articles for potential inclusion in our systematic review and meta-analysis. After excluding 9 articles with reasons, including 2 previous systematic reviews and metaanalyses and a recently retracted paper, we ended up with 25 records to be included in our qualitative and quantitative synthesis. No completed randomized controlled trials were identified; thus, we included only observational studies in our synthesis.

Nine studies were conducted in Europe (UK, Italy, France, Spain, Belgium) [18-26], 7 studies took place in North America (the USA) [27-33], while 9 studies were conducted in Asia, mainly in China [31, 34-41]. Finally, we initially included in our quantitative synthesis a study utilizing data from an observational database from 169 hospitals in Asia, Europe, and North America, which was recently retracted and thus excluded from our analysis [42]. Summary of studies' characteristics is provided in Table 1, while quality assessment with the use of NOS is provided in Table 2.

Herein, we present the main findings of our quantitative synthesis.

\section{ACE Inhibitors/ARBs vs. Non-ACE Inhibitors/ARBs and Outcomes of Clinical Significance}

\section{SARS-CoV-2 Testing Positive}

Use of ACE inhibitors or ARBs is not associated with increased odds for testing positive for SARS-CoV-2 (OR =
$0.99,95 \%$ CI $0.83-1.17, I^{2}=93 \%$ ), as shown in Fig. 2a. Subgroup analysis according to region did not reveal any significant association between ACE inhibitors/ARBs use and SARS-CoV-2-positive testing (in Asia, OR $=0.76,95 \% \mathrm{CI}$ $0.54-1.07, I^{2}=84 \%$; in Europe, OR $=1.22,95 \%$ CI $0.77-$ $1.95, I^{2}=97 \%$; in North America, OR $=0.99,95 \%$ CI 0.86 $\left.1.15, I^{2}=62 \%\right)$. Inspection of the corresponding funnel plot for this primary outcome ruled out the presence of publication bias (supplementary figure 1).

\section{Hospital Admission}

Notably, use of ACE inhibitors or ARBs does not increase the odds for hospitalization in the context of SARS-CoV-2 infection $\left(\mathrm{OR}=1.74,95 \%\right.$ CI $\left.0.95-3.17, I^{2}=96 \%\right)$, as depicted in Fig. 2b.

\section{Severe or Critical Illness}

Despite inconsistency in definitions and reporting across the included studies, it was observed that the use of either ACE

Table 2 Newcastle-Ottawa quality assessment Form regarding included studies

\begin{tabular}{|c|c|c|c|}
\hline Study & Selection & Comparability & Outcome \\
\hline Bean et al. & 3 & 2 & 1 \\
\hline Benelli et al. & 3 & 2 & 1 \\
\hline Caraballo et al. & 3 & 2 & 1 \\
\hline Chen et al. & 3 & 2 & 1 \\
\hline Dauchet et al. & 3 & 2 & 1 \\
\hline De Abajo et al. & 3 & 2 & 1 \\
\hline deSpiegeleer et al. & 2 & 2 & 1 \\
\hline Ebinger et al. & 2 & 2 & 1 \\
\hline Feng et al. & 2 & 2 & 1 \\
\hline Huh et al. & 3 & 2 & 0 \\
\hline Ip et al. & 2 & 0 & 1 \\
\hline Khawaja et al. & 3 & 2 & 1 \\
\hline Khera et al. & 3 & 2 & 2 \\
\hline Li et al. & 3 & 2 & 1 \\
\hline Liu et al. & 2 & 0 & 1 \\
\hline Mancia et al. & 3 & 2 & 1 \\
\hline Mehta et al. & 3 & 2 & 1 \\
\hline Meng et al. & 2 & 0 & 1 \\
\hline Raisi et al. & 3 & 2 & 1 \\
\hline Rentsch et al. & 3 & 2 & 1 \\
\hline Reynolds et al. & 2 & 2 & 1 \\
\hline Rossi et al. & 3 & 2 & 3 \\
\hline Yan et al. & 3 & 2 & 1 \\
\hline Yang et al. & 3 & 2 & 1 \\
\hline Zhou et al. & 2 & 2 & 1 \\
\hline
\end{tabular}


inhibitors or ARBs is not associated with increased odds for severe or critical illness $\left(\mathrm{OR}=0.86,95 \%\right.$ CI $0.64-1.16, I^{2}=$ $90 \%$ ), as shown in Fig. 2c. Of note, use of ACE inhibitors/ ARBs in Asia was associated with a significant reduction in the odds for severe or critical illness by $63 \%(\mathrm{OR}=0.37,95 \%$ CI $0.16-0.89, I^{2}=83 \%$ ), whereas, such an association was not shown in Europe $\left(\mathrm{OR}=1.12,95 \%\right.$ CI $\left.0.51-2.47, I^{2}=94 \%\right)$ and in North America $\left(\mathrm{OR}=1.11,95 \%\right.$ CI $0.84-1.45, I^{2}=$ $85 \%)$.

\section{ICU Admission}

It was also demonstrated that administration of ACE inhibitors or ARBs does not increase the odds for admission to ICU ( $\mathrm{OR}=1.40,95 \%$ CI $\left.0.80-2.43, I^{2}=86 \%\right)$, as shown in Fig. $2 \mathrm{~d}$. Notably, in subgroup analysis by region, it was shown that ACE inhibitors/ARBs use is associated with increased odds for ICU admission in North America $(\mathrm{OR}=1.75,95 \% \mathrm{CI}$ $1.37-2.23, I^{2}=0 \%$, while this association appeared nonsignificant in Europe $\left(\mathrm{OR}=1.11,95 \%\right.$ CI $0.33-3.79, I^{2}=$ $92 \%)$.

\section{SARS-CoV-2-Related Death}

Of note, use of ACE inhibitors or ARBs does not increase the odds for SARS-CoV-2-related death $(\mathrm{OR}=1.06,95 \% \mathrm{CI}$ $0.63-1.43, I^{2}=83 \%$ ), as depicted in Fig. 2e. However, in subgroup analysis by region, it was shown that ACE inhibitors/ ARBs use increases the odds for death in Europe by $68 \%$ $\left(\mathrm{OR}=1.68,95 \%\right.$ CI $\left.1.05-2.70, I^{2}=82 \%\right)$, it decreases the corresponding odds in Asia by $38 \%(\mathrm{OR}=0.62,95 \% \mathrm{CI}$ $0.39-0.99, I^{2}=0 \%$ ), whereas the association remains nonsignificant in the USA $\left(\mathrm{OR}=0.95,95 \% \mathrm{CI} 0.63-1.43, I^{2}=\right.$ $84 \%)$.

\section{Another Dilemma: ACE Inhibitors or ARBs}

\section{SARS-CoV-2 Testing Positive}

No significant difference was detected in the odds for SARSCoV-2-positive testing among users of ACE inhibitors or ARBs $\left(\mathrm{OR}=0.96,95 \%\right.$ CI $\left.0.87-1.05, I^{2}=38 \%\right)$, as shown in Fig. 3a. Notably, no significant difference was observed in the subgroup analysis by region (in Asia, OR $=1.08,95 \%$ CI $0.81-1.45, I^{2}=0 \%$; in Europe, OR $=0.91,95 \%$ CI $0.73-$ $1.14, I^{2}=68 \%$; and in North America, OR $=1.01,95 \% \mathrm{CI}$ $\left.0.90-1.12, I^{2}=0 \%\right)$.

\section{Admission to ICU}

No significant difference in the odds for admission to ICU between subjects receiving ACE inhibitors or ARBs was detected $\left(\mathrm{OR}=0.73,95 \%\right.$ CI $\left.0.35-1.56, I^{2}=43 \%\right)$, as depicted in Fig. 3b.

\section{SARS-CoV-2-Related Death}

Of interest, ACE inhibitors were found to be superior to ARBs in SARS-CoV-2-related death, although the result is marginally insignificant $\left(\mathrm{OR}=0.86,95 \% \mathrm{CI} 0.74-1.00, I^{2}=0 \%\right)$, as shown in Fig. 3c.

\section{Discussion}

This is the first systematic review and meta-analysis of all available observational studies (published up to 19 May 2020), assessing the association of RAS inhibitors with the whole spectrum of COVID-19 (infection, hospitalization, severity, death), and also providing two very significant pieces of information: geographical variation and a comparison between ACE inhibitors and ARBs.

Ever since the evolution of this pandemic, ACE inhibitors and ARBs have been at the epicenter of attention, due to the connection of SARS-CoV-2 with ACE2, an enzyme that is implicated in the degradation of angiotensin II (Ang II) to Ang (1-7) and Ang I to Ang (1-9) resulting in reductions in blood pressure, vasodilation, increased renal sodium excretion, and suppression of inflammation [44]. ACE2 serves as a host receptor for SARS-CoV-2, and it was initially hypothesized that ACE inhibitors and ARBs could mediate SARS-CoV-2 infection through upregulation in ACE2 expression [6, 45]. However, at the same time, ACE2 could serve as a protective mechanism towards lung injury, through increased cleavage of Ang I and II with subsequent reduced vasoconstriction and inflammation [46]. Of note, our analysis demonstrated that ACE inhibitors/ARBs do not correlate with increased odds for SARS-CoV-2-positive testing, hospitalization, severe or critical illness, ICU admission, and death.

While the aforementioned findings regarding positive testing apply similarly to different regions, this is not the case for the rest outcomes. A reduction in the odds for severe or critical illness and death with the use of ACE inhibitors/ARBs was found for Asia and, on the contrary, use of ACE inhibitors/ARBs increased the odds for ICU admission in North America and related death in Europe. Could these generated differences be attributed to the different ethnic and racial composition of the population of the included studies? Central Asia has the highest burden of cardiovascular disease, when compared with Europe and North America [47], while racial differences have been reported among SARS-CoV-2-positive patients, such as that black race doubles the odds for 


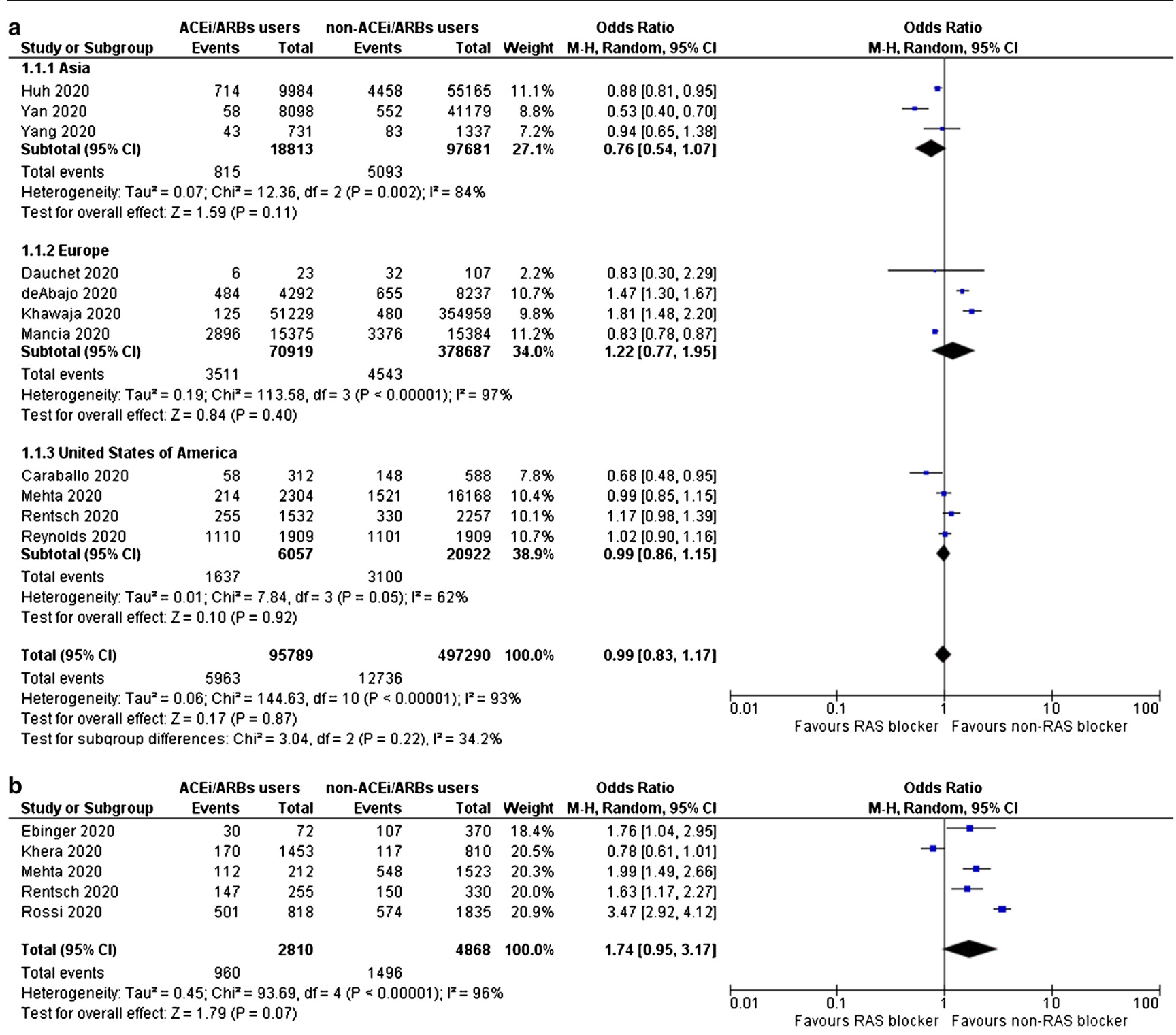

Fig. 2 a Odds for SARS-CoV-2-positive testing, $\mathbf{b}$ odds for admission to hospital, $\mathbf{c}$ odds for severe or critical illness, $\mathbf{d}$ odds for admission to ICU, and $\mathbf{e}$ odds for SARS-CoV-2-related death, for ACE inhibitors/ARBs users compared with non-users

hospital admission [48]. However, based on current evidence, it is unclear whether the use of ACE inhibitors or ARBs plays a role. Unfortunately, such a subgroup analysis could not be performed due to inadequate data reporting across the selected studies.

Another issue of concern is whether differences exist regarding SARS-CoV-2 infection outcomes among users of ACE inhibitors and ARBs. Alternate responses of ACE2 and Ang (1-7) were documented in an experimental model utilizing Lewis rats after the administration of lisinopril and losartan. More specifically, administration of an ACE inhibitor caused a 1.8 increase in Ang (1-7) and a 4.7-fold rise in cardiac ACE2 mRNA, although cardiac ACE2 activity remained unchanged. On the other hand, apart from Ang (1-7) and cardiac ACE2 mRNA, administration of an ARB increased cardiac ACE2 activity [49]. In our analysis, no significant differences were observed among ACE inhibitors and ARBs regarding odds for SARS-CoV-2-positive testing, ICU admission, and death, although there was an observed trend towards reduced odds for death with the use of ACE inhibitors. Nevertheless, results from ongoing phase 4 clinical trials that aim to assess the effects of losartan and valsartan on progression of acute respiratory distress syndrome are eagerly awaited (NCT04340557 and NCT04335786).

Two other meta-analyses have been published recently assessing the effects of ACE inhibitors and ARBs on mortality, critical or fatal outcome, and hospitalization. More specifically, Abdulhak et al. conducted a meta-analysis regarding the effects of ACE inhibitors/ARBs on mortality 


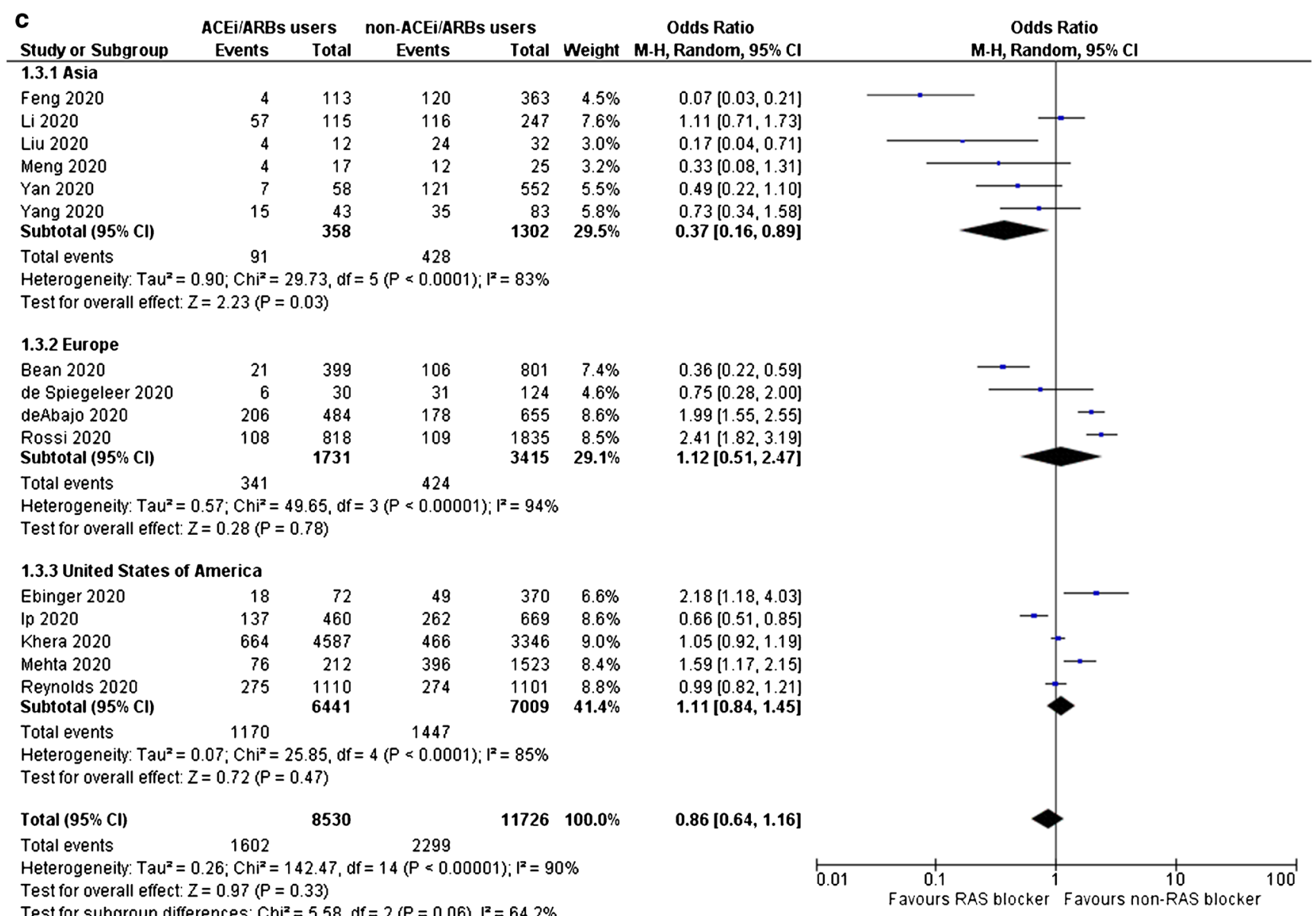

Test for subgroup differences: $\mathrm{Chi}^{2}=5.58, \mathrm{df}=2(\mathrm{P}=0.06), \mathrm{I}^{2}=64.2 \%$

Fig. 2 (continued)

and a critical or fatal outcome. Interestingly, ACE inhibitors and ARBs were associated with reduced odds for inpatient mortality and a critical or fatal outcome $(\mathrm{OR}=0.33$, $95 \%$ CI $0.22-0.49, I^{2}=0 \%$, and OR $=0.32,95 \%$ CI $0.22-$ $0.46, I^{2}=32 \%$, respectively) [50]. Similarly, Ghosal et al. found a significant decrease in the odds for death with the use of ACE inhibitors/ARBs (OR $=0.57,95 \%$ CI $0.37-$ $0.88, I^{2}=0 \%$ ), while non-significant benefits were also observed in terms of developing severe disease or hospitalization $\left(\mathrm{OR}=0.62,95 \% \mathrm{CI} 0.31-1.23, I^{2}=70.36 \%\right.$, and $\mathrm{OR}=0.81,95 \%$ CI $0.42-1.55, I^{2}=0 \%$, respectively) [51]. Nevertheless, the former meta-analysis included five and the latter six studies, most of which were located in China. This could probably explain the reported different results among these and our meta-analysis, which included studies not only from China but also from Europe and North America, resulting in a larger sample size and enabling subgroup analysis among different continents.

Our meta-analysis has certain limitations. First, we included only observational studies; however, no randomized controlled studies are available so far. Forthcoming randomized controlled trials will shed further light on the association between ACE inhibitors/ARBs use and significant SARSCoV-2-related clinical outcomes. Such RCTs are under way, after a thorough research of grey literature sources (ClinicalTrials.gov Identifier: NCT04353596, NCT04364893, NCT04345406, NCT04351581, NCT04338009, NCT04329195, NCT04493359, NCT04510662, NCT04366050, NCT04351724, NCT04355429), while some of them have been unfortunately suspended (ClinicalTrials.gov Identifier: NCT04330300). Second, heterogeneity is considered as high for most assessed outcomes; however, alternate pooling methods (switching from random to fixed effects formula) did not affect generated results. Finally, inconsistency of outcomes' reporting and selected definitions across the included studies did not permit us to perform subgroup analyses according to gender (male/female), race (white, black, Asian, other), or pre-existing co-morbidities (cardiovascular disease, chronic kidney disease, chronic respiratory failure, diabetes mellitus). The aforementioned constituted the investigation of sources of heterogeneity on outcomes of interest inevitable, potentially limiting the applicability of our results on general clinical practice. 


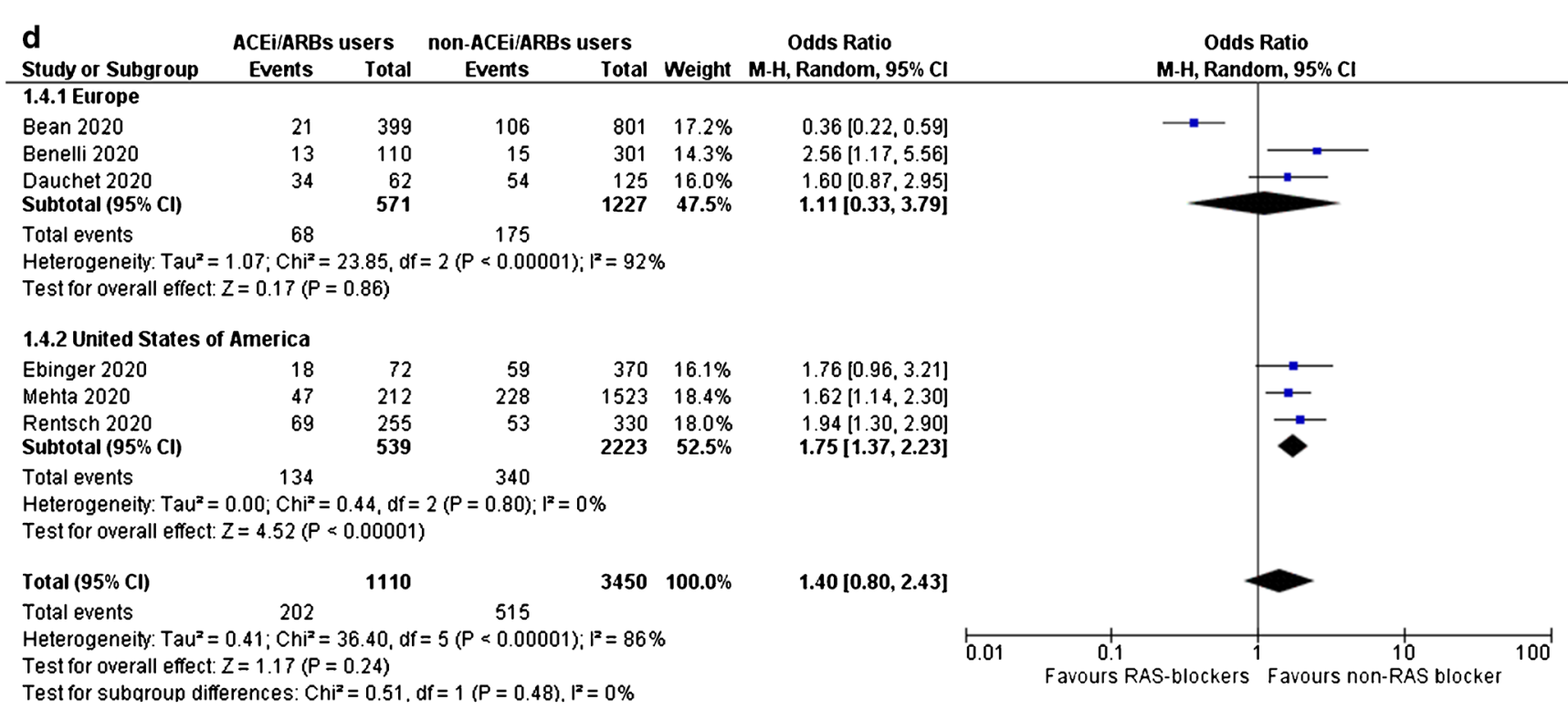

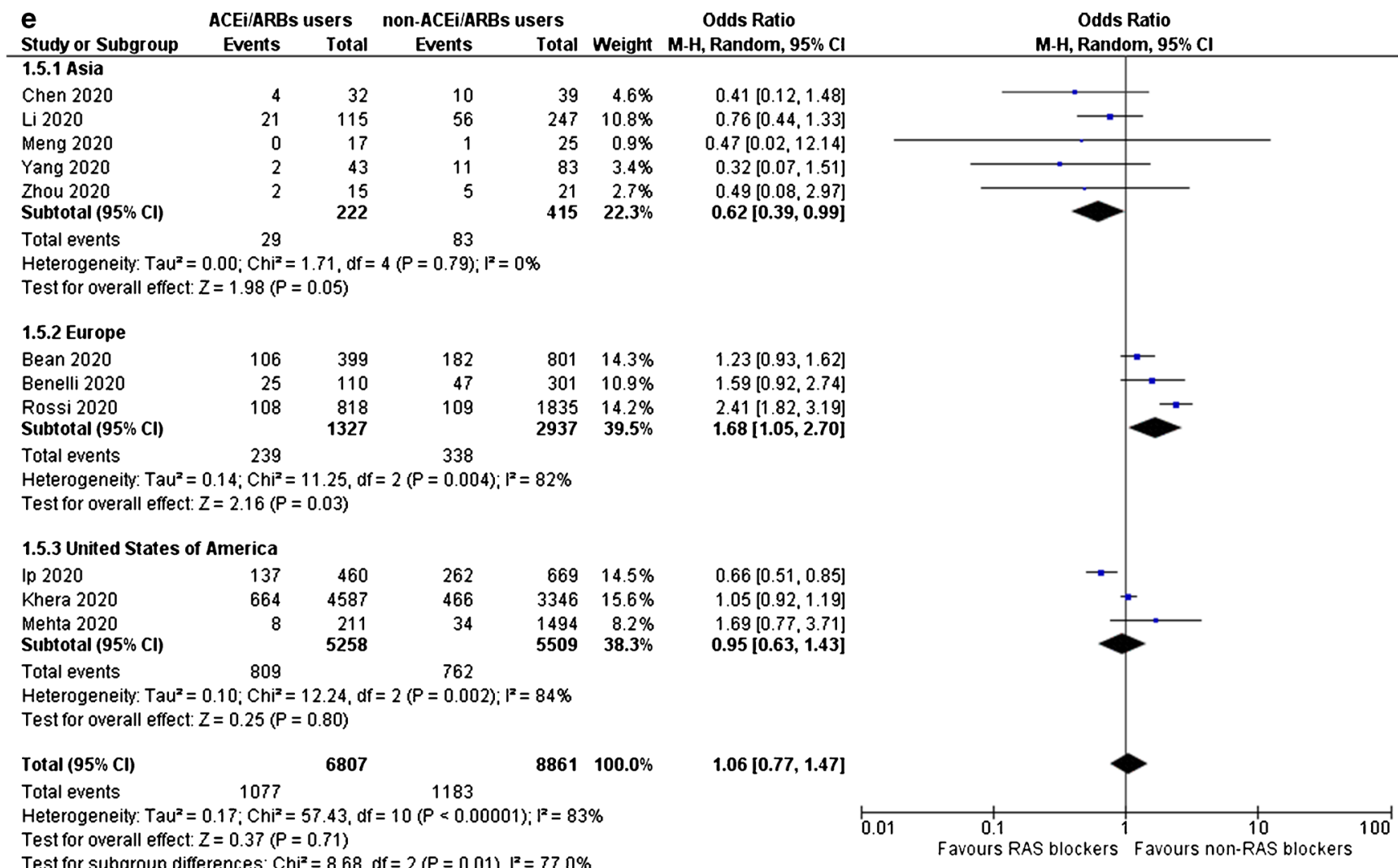

Fig. 2 (continued)

\section{Conclusion}

Overall, ACE inhibitors and ARBs had neutral effects on the odds for SARS-CoV-2 infection, admission to hospital, severe or critical illness, admission to ICU, or SARS-CoV-2-related death. However, subgroup analysis revealed differences among different continents; as in Asian countries, they

decreased the odds for severe or critical illness and death, while in North America and Europe, they increased the odds for ICU admission and death, respectively. No differences were detected between ACE inhibitors and ARBs, except marginally insignificant protection with the use of ACE inhibitors towards SARS-CoV-2-related death. Collectively, the findings of the present meta-analysis challenge the 
a

Study or Subgroup Events Total Events Total Weight $\mathrm{M}-\mathrm{H}$, Random, $95 \% \mathrm{Cl}$

\begin{tabular}{|c|c|c|c|c|c|}
\hline \multicolumn{6}{|l|}{ 2.1.1 Asia } \\
\hline Huh 2020 & 46 & 653 & 668 & 10045 & $7.8 \%$ \\
\hline $\begin{array}{l}\text { Yan } 2020 \\
\text { Subtotal }(95 \% \mathrm{Cl})\end{array}$ & 5 & $\begin{array}{r}560 \\
1213\end{array}$ & 53 & 17583 & $\begin{array}{l}1.1 \% \\
8.9 \%\end{array}$ \\
\hline \multicolumn{6}{|c|}{$\begin{array}{l}\text { Heterogeneity: } \text { Tau }^{2}=0.00 ; \mathrm{Chi}^{2}=0.13, \mathrm{df}=1(\mathrm{P}=0.72) ; \mathrm{I}^{2}=0 \% \\
\text { Test for overall effect: } Z=0.53(P=0.59)\end{array}$} \\
\hline \multicolumn{6}{|l|}{ 2.1.2 Europe } \\
\hline Dauchet 2020 & 4 & 12 & 2 & 11 & $0.2 \%$ \\
\hline deAbajo 2020 & 240 & 2432 & 244 & 1860 & $15.4 \%$ \\
\hline Khawaja 2020 & 86 & 33827 & 39 & 17402 & $5.6 \%$ \\
\hline $\begin{array}{l}\text { Mancia } 2020 \\
\text { Subtotal }(95 \% \mathrm{Cl})\end{array}$ & 1502 & $\begin{array}{r}8071 \\
44342\end{array}$ & 1394 & $\begin{array}{r}7304 \\
26577\end{array}$ & $\begin{array}{l}29.3 \% \\
50.6 \%\end{array}$ \\
\hline Total events & 1832 & & 1679 & & \\
\hline
\end{tabular}

Heterogeneity: $\mathrm{Tau}^{2}=0.03 ; \mathrm{Chi}^{2}=9.47, \mathrm{df}=3(\mathrm{P}=0.02) ; \mathrm{I}^{2}=68 \%$

Test for overall effect: $Z=0.78(P=0.43)$

\subsubsection{United States of America}

$\begin{array}{lrlrrr}\text { Mehta 2020 } & 116 & 1322 & 98 & 982 & 9.0 \% \\ \text { Rentsch 2020 } & 169 & 1011 & 94 & 563 & 9.3 \% \\ \text { Reynolds 2020 } & 627 & 2088 & 664 & 2274 & 22.2 \% \\ \text { Subtotal (95\% CI) } & & 4421 & & \mathbf{3 8 1 9} & \mathbf{4 0 . 5 \%} \\ \text { Total events } & 912 & & 856 & & \end{array}$

Heterogeneity: $\mathrm{Tau}^{2}=0.00 ; \mathrm{Chi}^{2}=1.31, \mathrm{df}=2(\mathrm{P}=0.52) ; \mathrm{I}^{2}=0 \%$

Test for overall effect: $Z=0.13(P=0.90)$ $\begin{array}{llcrr}\text { Total }(95 \% \mathrm{Cl}) & 49976 & 47979 & 100.0 \% \\ \text { Total events } & 2795 & 3256 & \end{array}$

Heterogeneity: $\mathrm{Tau}^{2}=0.01 ; \mathrm{Chi}^{2}=12.80, \mathrm{df}=8(\mathrm{P}=0.12) ; \mathrm{I}^{2}=38 \%$

Test for overall effect: $Z=0.92(P=0.36)$

Test for subgroup differences: $\mathrm{Chi}^{2}=0.91, \mathrm{df}=2(\mathrm{P}=0.63), \mathrm{I}^{2}=0 \%$
Odds Ratio

Odds Ratio

M-H, Random, $95 \%$ Cl

$2.25[0.32,15.76]$

$0.73[0.60,0.88]$

$1.13[0.78,1.66]$

$0.97[0.89,1.05]$

$0.91[0.73,1.14]$

$0.87[0.65,1.15]$

$1.00[0.76,1.32]$

$1.04[0.91,1.19]$

$1.01[0.90,1.12]$

$0.96[0.87,1.05]$

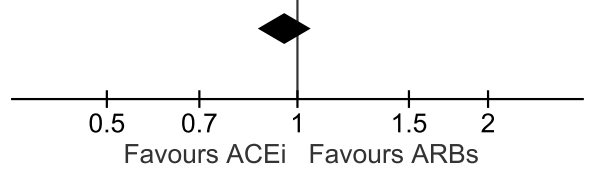

Odds Ratio

Odds Ratio

b

ACEi ARBs

M-H, Random, $95 \% \mathrm{Cl}$

M-H, Random, $95 \%$ Cl

\begin{tabular}{lrrrrr} 
Study or Subgroup & Events & Total & Events & Total & Weight \\
\hline Benelli 2020 & 11 & 50 & 14 & 60 & $12.4 \%$ \\
Khera 2020 & 319 & 2361 & 345 & 2226 & $32.4 \%$ \\
Li 2020 & 7 & 35 & 15 & 83 & $10.7 \%$ \\
Mehra 2020 & 16 & 770 & 38 & 556 & $19.3 \%$ \\
Rossi 2020 & 56 & 450 & 52 & 368 & $25.2 \%$ \\
Zhou 2020 & 0 & 0 & 0 & 0 & \\
Total (95\% Cl) & & 3666 & & 3293 & $100.0 \%$ \\
Total events & 409 & & 464 & &
\end{tabular}

Heterogeneity: $\mathrm{Tau}^{2}=0.12 ; \mathrm{Chi}^{2}=12.50, \mathrm{df}=4(\mathrm{P}=0.01) ; \mathrm{I}^{2}=68 \%$

Test for overall effect: $Z=1.61(P=0.11)$

$0.93[0.38,2.27]$

$0.85[0.72,1.00]$

$1.13[0.42,3.08]$

$0.29[0.16,0.52]$

$0.86[0.58,1.30]$

Not estimable

$0.72[0.49,1.07]$

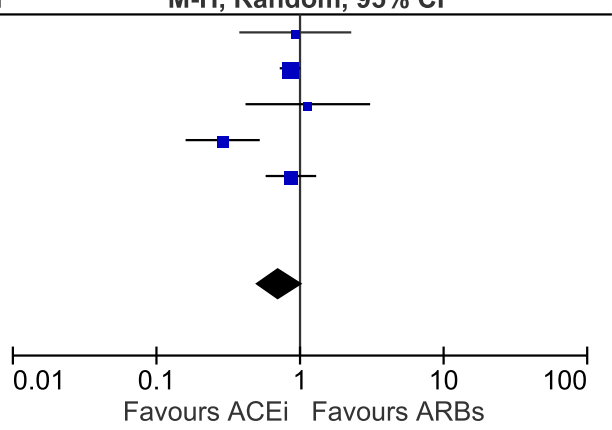

C

ACEi

ARBs

Odds Ratio

Study or Subgroup Events Total Events Total Weight $\mathrm{M}-\mathrm{H}, \mathrm{Random}, 95 \% \mathrm{Cl}$

Benelli 2020

Ebinger 2020

$4 \quad 50$

$9 \quad 60 \quad 24.7 \%$

$0.49[0.14,1.71]$

$0.41[0.13,1.32]$

Mehta 2020

$\begin{array}{rr}5 & 31 \\ 28 & 116\end{array}$

$13 \quad 41 \quad 27.0 \%$

$20 \quad 98 \quad 48.3 \%$

$1.24[0.65,2.38]$

Total $(95 \% \mathrm{Cl})$

197

$199 \quad 100.0 \%$

$0.73[0.35,1.56]$

$37 \quad 42$

Heterogeneity: $\mathrm{Tau}^{2}=0.20 ; \mathrm{Chi}^{2}=3.52, \mathrm{df}=2(\mathrm{P}=0.17) ; \mathrm{I}^{2}=43 \%$

Test for overall effect: $Z=0.80(P=0.42)$

Fig. 3 a Odds for SARS-CoV-2-positive testing, $\mathbf{b}$ odds for admission to ICU, and $\mathbf{c}$ odds for SARS-CoV-2-related death, for ACE inhibitors users compared with ARBs users 
recommendations of American and European Scientific Associations on the use of RAS inhibitors in the COVID-19 era. However, as all studies that were included in our analysis were observational, well-designed, randomized, controlled studies are needed to confirm or oppose these results.

Authors' Contribution MD conceived and designed the study. DP and AK performed the scientific literature search. DP and AK did literature screening. DP, AK, and KS extracted data and performed quality assessment of the included studies. DP did the analyses. DP and AK wrote the first draft of the report. MD, DP, KI, and MK contributed to interpretation and edited the draft report. All authors approved the final form of the paper before submission.

\section{Compliance with Ethical Standards}

Conflict of Interest The authors declare that they have no conflicts of interest.

Human and Animal Rights and Informed Consent This article does not contain any studies with human or animal subjects performed by any of the authors.

\section{References}

1. Zhu N, Zhang D, Wang W, Li X, Yang B, Song J, et al. A novel coronavirus from patients with pneumonia in China, 2019. N Engl J Med. 2020;382:727-33.

2. WHO Coronavirus Disease (COVID-19) Dashboard. World Health Organization, Assessed on May 27th, 2020. https://covid19.who. int/. Accessed 27 May 2020.

3. Li W, Moore MJ, Vasilieva N, Sui J, Wong SK, Berne MA, et al. Angiotensin-converting enzyme 2 is a functional receptor for the SARS coronavirus. Nature. 2003;426:450-4.

4. Hoffmann M, Kleine-Weber H, Schroeder S, et al. SARS-CoV-2 cell entry depends on ACE2 and TMPRSS2 and is blocked by a clinically proven protease inhibitor. Cell. 2020;181:271-80.e8.

5. Wrapp D, Wang N, Corbett KS, Goldsmith JA, Hsieh CL, Abiona O, et al. Cryo-EM structure of the 2019-nCoV spike in the prefusion conformation. Science. 2020;367:1260-3.

6. Fang L, Karakiulakis G, Roth M. Are patients with hypertension and diabetes mellitus at increased risk for COVID-19 infection? Lancet Respir Med. 2020;8:e21.

7. Esler M, Esler D. Can angiotensin receptor-blocking drugs perhaps be harmful in the COVID-19 pandemic? J Hypertens. 2020;38: $781-2$.

8. Aronson JK, Ferner RE. Drugs and the renin-angiotensin system in Covid-19. BMJ. 2020;369:m1313.

9. Gheblawi M, Wang K, Viveiros A, Nguyen Q, Zhong JC, Turner $\mathrm{AJ}$, et al. Angiotensin-converting enzyme 2: SARS-CoV-2 receptor and regulator of the renin-angiotensin system: celebrating the 20th anniversary of the discovery of ACE2. Circ Res. 2020;126:145674.

10. Vaduganathan M, Vardeny O, Michel T, McMurray JJV, Pfeffer MA, Solomon SD. Renin-angiotensin-aldosterone system inhibitors in patients with Covid-19. N Engl J Med. 2020;382:1653-9.

11. Zheng YY, Ma YT, Zhang JY, Xie X. COVID-19 and the cardiovascular system. Nat Rev Cardiol. 2020;17:259-60.

12. Moher D, Liberati A, Tetzlaff J, Altman DG, PRISMA Group. Preferred reporting items for systematic reviews and meta-analyses: the PRISMA statement. BMJ. 2009;339:b2535.
13. McGowan J, Sampson M, Salzwedel DM, Cogo E, Foerster V, Lefebvre C. PRESS peer review of electronic search strategies: 2015 guideline statement. J Clin Epidemiol. 2016;75:40-6.

14. Higgins JPT, Sterne JAC, Savović J, et al. A revised tool for assessing risk of bias in randomized trials. Cochrane Database Syst Rev. 2016;10(Suppl 1):29-31.

15. Wells G, Shea B, O'Connell D, et al. The Newcastle-Ottawa scale (NOS) for assessing the quality of nonrandomised studies in metaanalyses. 2013. http://www.ohri.ca/programs/clinical_ epidemiology/oxford.asp. Accessed 19 May 2020.

16. Deeks JJ, Higgins JPT, Altman DG. Chapter 9: analyzing data and undertaking meta-analyses. In: Higgins JPT, Green S (eds) Cochrane handbook for systematic reviews of interventions version 5.1.0 [updated March 2011], The Cochrane Collaboration. 2011.

17. Review Manager (RevMan) [Computer program] Version [5.3] Copenhagen: The Nordic Cochrane Centre TCC; 2014.

18. Bean D, Kraljevic Z, Searle T, et al. ACE-inhibitors and Angiotensin-2 Receptor Blockers are not associated with severe SARS- COVID19 infection in a multi-site UK acute Hospital Trust. MedRxiv. 2020. https://doi.org/10.1101/2020.04.07. 20056788

19. Benelli G, Buscarini E, Canetta C, et al. SARS-COV-2 comorbidity network and outcome in hospitalized patients in Crema, Italy. MedRxiv. 2020. https://doi.org/10.1101/2020.04.14.20053090.

20. Dauchet L, Lambert M, Gauthier V, et al. ACE inhibitors, AT1 receptor blockers and COVID-19: clinical epidemiology evidences for a continuation of treatments. The ACER-COVID study. MedRxiv. 2020. https://doi.org/10.1101/2020.04.28.20078071.

21. de Abajo FJ, Rodríguez-Martín S, Lerma V, Mejía-Abril G, Aguilar M, García-Luque A, et al. Use of renin-angiotensin-aldosterone system inhibitors and risk of COVID-19 requiring admission to hospital: a case-population study. Lancet. 2020;395:1705-14.

22. De Spiegeleer A, Bronselaer A, Teo JT, et al. The effects of ARBs, ACEIs and statins on clinical outcomes of COVID-19 infection among nursing home residents. MedRxiv. 2020. https://doi.org/ 10.1101/2020.05.11.20096347.

23. Khawaja AP, Warwick AN, Hysi PG, et al. Associations with Covid-19 hospitalisation amongst 406,793 adults: the UK Biobank prospective cohort study. MedRxiv. 2020. https://doi. org/10.1101/2020.05.06.20092957.

24. Mancia G, Rea F, Ludergnani M, Apolone G, Corrao G. Reninangiotensin-aldosterone system blockers and the risk of Covid-19. N Engl J Med. 2020;382:2431-40.

25. Raisi-Estabragh Z, McCracken C, Ardissino M, et al. Non-white ethnicity, male sex, and higher body mass index, but not medications acting on the renin-angiotensin system are associated with coronavirus disease 2019 (COVID-19) hospitalisation: review of the first 669 cases from the UK BIOBANK. MedRxiv. 2020. https://doi.org/10.1101/2020.05.10.20096925.

26. Giorgi Rossi P, Marino M, Formisano D, et al. Characteristics and outcomes of a cohort of SARS-CoV-2 patients in the province of Reggio Emilia, Italy. MedRxiv. 2020. https://doi.org/10.1101/ 2020.04.13.20063545.

27. Caraballo C, McCullough M, Fuery M, et al. COVID-19 infections and outcomes in a live registry of heart failure patients across an integrated health care system. MedRxiv. 2020. https://doi.org/10. 1101/2020.04.27.20082016.

28. Ebinger JE, Achamallah N, Ji H, et al. Pre-existing traits associated with Covid-19 illness severity. MedRxiv. 2020. https://doi.org/10. 1101/2020.04.29.20084533.

29. Ip A, Parikh K, Parrillo JE, et al. Hypertension and reninangiotensin-aldosterone system inhibitors in patients with Covid19. MedRxiv. 2020. https://doi.org/10.1101/2020.04.24. 20077388.

30. Khera R, Clark C, Lu Y, et al. Association of angiotensinconverting enzyme inhibitors and angiotensin receptor blockers 
with the risk of hospitalization and death in hypertensive patients with coronavirus disease-19. MedRxiv. 2020. https://doi.org/10. 1101/2020.05.17.20104943.

31. Liu Y, Huang F, Xu J, et al. Anti-hypertensive Angiotensin II receptor blockers associated to mitigation of disease severity in elderly COVID-19 patients. MedRxiv. 2020. https://doi.org/10.1101/ 2020.03.20.20039586.

32. Rentsch CT, Kidwai-Khan F, Tate JP, et al. Covid-19 testing, hospital admission, and intensive care among 2,026,227 United States veterans aged 54-75 years. MedRxiv. 2020. https://doi.org/10. 1101/2020.04.09.20059964.

33. Reynolds HR, Adhikari S, Pulgarin C, Troxel AB, Iturrate E, Johnson SB, et al. Renin-angiotensin-aldosterone system inhibitors and risk of Covid-19. N Engl J Med. 2020;382:2441-8.

34. Chen Y, Yang D, Cheng B, Chen J, Peng A, Yang C, et al. Clinical characteristics and outcomes of patients with diabetes and COVID19 in association with glucose-lowering medication. Diabetes Care. 2020;43:1399-407.

35. Feng Y, Ling Y, Bai T, et al. COVID-19 with different severities: a multi-center study of clinical features. Am J Respir Crit Care Med. 2020; published online Apr 10. https://doi.org/10.1164/rccm. 202002-0445OC.

36. Huh K, Ji W, Kang M, et al. Association of previous medications with the risk of COVID-19: a nationwide claims-based study from South Korea. MedRxiv. 2020. https://doi.org/10.1101/2020.05.04. 20089904.

37. Li J, Wang X, Chen J, Zhang H, Deng A. Association of reninangiotensin system inhibitors with severity or risk of death in patients with hypertension hospitalized for coronavirus disease 2019 (COVID-19) infection in Wuhan, China. JAMA Cardiol. 2020; published online Apr 23. https://doi.org/10.1001/jamacardio.2020. 1624.

38. Mehta N, Kalra A, Nowacki AS, et al. Association of use of angiotensin-converting enzyme inhibitors and angiotensin II receptor blockers with testing positive for coronavirus disease 2019 (COVID-19). JAMA Cardiol. 2020; published online May 5. https://doi.org/10.1001/jamacardio.2020.1855.

39. Yan H, Valdes AM, Vijay A, et al. Role of drugs affecting the renin-angiotensin-aldosterone system on susceptibility and severity of COVID-19: a large case-control study from Zheijang Province, China. MedRxiv. 2020. https://doi.org/10.1101/2020.04.24. 20077875.

40. Yang G, Tan Z, Zhou L, et al. Effects of ARBs and ACEIs on virus infection, inflammatory status and clinical outcomes in COVID-19 patients with hypertension: a single center retrospective study. Hypertension. 2020;76:51-8.
41. Zhou X, Zhu J, Xu T. Clinical characteristics of coronavirus disease 2019 (COVID-19) patients with hypertension on renin-angiotensin system inhibitors. Clin Exp Hypertens. 2020;42:656-60.

42. Mehra MR, Desai SS, Kuy S, Henry TD, Patel AN. Retraction: cardiovascular disease, drug therapy, and mortality in Covid-19. N Engl J Med. DOI: 10.1056/NEJMoa2007621 [published online ahead of print, 2020 Jun 4] [retraction of: N Engl J Med. 2020 May 1;.. N Engl J Med. 2020:NEJMc2021225. https://doi.org/10. 1056/NEJMc2021225.

43. Meng J, Xiao G, Zhang J, He X, Ou M, Bi J, et al. Reninangiotensin system inhibitors improve the clinical outcomes of COVID-19 patients with hypertension. Emerg Microbes Infect. 2020;9:757-60.

44. South AM, Tomlinson L, Edmonston D, Hiremath S, Sparks MA. Controversies of renin-angiotensin system inhibition during the COVID-19 pandemic. Nat Rev Nephrol. 2020;16:305-7.

45. Chen Y, Guo Y, Pan Y, Zhao ZJ. Structure analysis of the receptor binding of 2019-nCoV. Biochem Biophys Res Commun. 2020;525:135-40.

46. Furuhashi M, Moniwa N, Takizawa H, Ura N, Shimamoto K. Potential differential effects of renin-angiotensin system inhibitors on SARS-CoV-2 infection and lung injury in COVID-19. Hypertens Res. 2020;43:837-40. https://doi.org/10.1038/s41440020-0478-1.

47. Roth G, Huffman M, Moran A, et al. Global and regional patterns in cardiovascular mortality from 1990 to 2013. Circulation. 2015;132: 1667-78.

48. Price-Haywood EG, Burton J, Fort D, Seoane L. Hospitalization and mortality among black patients and white patients with Covid19. N Engl J Med. 2020; published online May 27. https://doi.org/ 10.1056/NEJMsa2011686.

49. Ferrario C, Jessup J, Chappell M, et al. Effect of angiotensinconverting enzyme inhibition and angiotensin II receptor blockers on cardiac angiotensin-converting enzyme 2. Circulation. 2005;111:2605-10.

50. Abdulhak AAB, Kashour T, Noman A, et al. Angiotensin converting enzyme inhibitors and angiotensin receptor blockers and outcome of COVID-19: a systematic review and meta-analysis. MedRxiv. 2020. https://doi.org/10.1101/2020.05.06.20093260.

51. Ghosal S, Mukherjee JJ, Sinha B, Gangopadhyay KK. The effect of angiotensin converting enzyme inhibitors and angiotensin receptor blockers on death and severity of disease in patients with coronavirus disease 2019 (COVID-19): a meta-analysis. MedRxiv. 2020. https://doi.org/10.1101/2020.04.23.20076661.

Publisher's Note Springer Nature remains neutral with regard to jurisdictional claims in published maps and institutional affiliations. 